\title{
INFLUÊNCIA DE DIFERENTES NÍVEIS DE VITAMINA C NA RACÃO SOBRE PARÂMETROS HEMATOLÓGICOS DE ALEVINOS DE PIARACTUS MESOPOTAMICUS HOLMBERG (OSTEICHTHYES, CHARACIDAE)
}

\author{
Maurício Laterça Martins 1 \\ Newton Castagnolli ${ }^{2,1}$ \\ Sônia Maria Fontes Zuim ${ }^{3,1}$ \\ Elisabeth Criscuolo Urbinati ${ }^{4,1}$
}

\begin{abstract}
INFLUENCE OF DIFFERENT LEVELS OF VITAMIN C IN THE RATION ON THE haEMATOlOgical PaRAMETERS OF PlaRACTUS MESOPOTAMICUS HOLMBERG (OSTEICHTHYES, ChARACIDAE) FRIES. Haematological changes in ascorbic acid deficient fishes, observed by some authors, awoked the interest in the haematological response of pacu. Piaractus mesopotamicts. The present work studied the influence of different levels of ascorbic acid (vitamin $C$ ) in the ration on the haematological parameters of pacu. Fishes at the beginning of the experiment, presented average body weight $8.64+1.62 \mathrm{~g}$ and $6.15+0.33 \mathrm{~cm}$ standard length. were fed with diets containing $0,50,100$ and $200 \mathrm{mg}$ ascorbic acid $/ \mathrm{kg}$ dry ration. The present work was developed for a period of 24 weeks at the Fish Nutrition Laboratory of Aquaculture Center of Universidade Estadual Paulista (Unesp), Jaboticabal (São Paulo). The fishes were distributed by the completely randomized design in 20 aquaria of 100 liters capacity with six animals in each and five fold treatment. Condutivity, alcalinity. $\mathrm{pH}$ and oxigen were measured weekly and temperature daily. The blood colect was done in 60 anesthetized fishes with $50 \mathrm{mg}$ MS-222/1. The results suggests that $50 \mathrm{mg}$ ascorbic acid/kg dry ration improved the mean corpuscular volume, mean corpuseular haemoglobin, mean corpuseular haemoglobin concentration and decreased haematocrit in unsupplemented fishes. although not differing significantly $(P>0.05)$. The erytrocyte diameter indicated the presence of macrocytic cells in unsupplemented fishes $(P<0.05)$ and the regression analysis showed too reduced neutrophils in unsupplemented ones. $50 \mathrm{mg}$ ascorbic acid/kg dry ration supplementation was enough to development and haematological responses. Furthtermore, the optimum level to the growth is $139 \mathrm{mg}$ vitamin $\mathrm{C} / \mathrm{kg}$ dry ration $(\mathrm{P}<0.05)$.
\end{abstract}

KEY WORDS. Osteichthyes, Characidae, Piaractus mesopotamicus, haematology, vitamin $C$, fish

1) Centro de Aquicultura, Universidade Estadual Paulista, Campus de Jaboticabal. Rodovia Carlos Tonanni kmı 05, 14870-000 Jaboticabal, São Paulo, Brasil.

2) Departamento de Zooteenia de não Ruminantes, Universidade Estadual Paulista, Campus de Jaboticabal. Rodovia Carlos Tonanni km 05, 14870-000) Jaboticabal, São Paulo, Brasil.

3) Departamneto de Zoologia, Instituto de Biociêneias. Universidade Estadual Paulista, Campus de Rio Claro. 13506-900 Rio Claro, São Paulo, Brasil.

4) Departamente de Morfologia e Fisiologia Animal, Universidade Estadual Paulista, Campus de Jaboticabal. Rodovia Carlos Tonanni km 05. 14870-000 Jaboticabal. São Paulo, Brasil. 
A ação da vitamina $\mathrm{C}$ em peixes tem sido motivo de estudos de vários autores através da histopatologia, hematologia, radiologia e da deficiência no crescimento. Millikin (1982), em ampla revisão bibliográfica, comprovou a importância da vitamina C para o bom funcionamento do sistema imunológico dos peixes, concluindo que a sua carência compromete o crescimento e aumenta a susceptibilidade às doenças. Lovell (1982), Durve \& Lovell (1982), Li \& LOVELL (1985), em Ictulurus punctutus Meyer, 1975 e NAVARRE \& HaLver (1989), em Solmo gairdneri Richardson, 1836 mostraram aumento na resistência de peixes alimentados com vitamina $C$ na dieta e diminuição da susceptibilidade às doenças bacterianas. LovELL \& LIM (1978) relataram que quanto maior a densidade de $l$. punctatus nos tanques de cultivo, maior é o seu requerimento vitamínico e a incidência de doenças, possivelmente devido ao estresse que a elevada densidade determina. ANDREWs \& MURAI (1975) e HilTon el al. (1978) observaram diminuição na taxa de hemoglobina e hematócrito dos peixes carentes em vitamina $C$, respectivamente em 1 . punctatus e $S$. gairdneri. AGRAWAL \& MAHAJAN (1980) destacaram a importância da suplementação de vitamina C para a carpa indiana (Cirrhina mrigala Hamilton, 1822) e notaram alterações na morfologia das células sangüíneas nos peixes deficientes em vitamina $\mathrm{C}$. Alterações na morfologia dos eritrócitos foram também observadas em Oncorhynchus mykiss Walhaum, 1792 por DABROWSKI et al. (1990). Ainda com relação à taxa de hemoglobina, ROSENLUND et al. (1990) observaram diminuição desta taxa em um lote de Pleuronectes platessa Linnaeus, 1758 sem suplementação de ácido ascórbico comparado com peixes submetidos à 200mg de ácido ascórbico/kg de ração, porém não houve diferença entre os que não receheram e os que receheram $2000 \mathrm{mg}$ de ácido ascórbico/kg de ração. EL NAGGAR \& LOVELL (1991) observaram que níveis de 11, 22, 44 e 132mg de ácido ascórbico/kg provocaram aumento no hematócrito de 1 . punctatus em relação aos peixes controle sem suplementação vitamínica. Estas observações também foram confirmadas mais tarde por MUSTIN \& Lovell ( 1992) na mesma espécie de peixe. Porém, nada se sabe sobre os efeitos da suplementação de vitamina C na ração para espécies brasileiras como Piaractus mesopotamicus Holmberg, 1887 (pacu) e Colossoma macropomum Cuvier, 1818 (tambaqui), que se encontram em expansão nos sistemas de cultivo. Recentemente MARTINS (no prelo) estudou os efeitos da vitamina $C$ sobre alterações no filamento branquial e comportamento de $P$. mesopotamicus. No presente trabalho foram avaliados diferentes parâmetros sangüíneos, tais como taxa de hemoglobina, número de eritrócitos, diâmetro de eritrócitos, hematócrito e contagem diferencial de leucócitos em alevinos de $P$. mesopotamicus, alimentados eom níveis de zero, 50, 100 e $200 \mathrm{mg}$ de ácido ascórbico/kg de ração.

\section{MATERIAL E MÉTODOS}

O experimento foi desenvolvido no Laboratório de Nutrição de Peixes do Centro de Aqüicultura da Universidade Estadual Paulista (Caunesp), Campus de Jahoticahal (São Paulo, Brasil) e teve a duração de 24 semanas.

Foram utilizados 120 alevinos de Piaractus mesopotanicus (pacu) prove- 
nientes de uma mesma desova, do próprio Caunesp, com peso médio de $8,64 \pm 1,62 \mathrm{~g}$ e comprimento padrão médio de $6,15 \pm 0,33 \mathrm{~cm}$, no início do experimento. Os peixes foram distribuídos em 20 aquários com capacidade de 100 litros, abastecidos com água declorificada e vazão de um litro por minuto. Diariamente foi aferida a temperatura, pela manhã e à tarde e semanalmente foram medidos: $\mathrm{pH}$, condutividade elétrica, alcalinidade e oxigênio dissolvido segundo método de GOLTERMAN et al. (1978). Para a distribuição dos animais nos aquários seguiu-se o delineamento inteiramente casualizado (DIC) com seis peixes em cada aquário e cinco repetições de cada tratamento. Todos os peixes receberam a mesma dieta (30\% de proteína bruta) com os mesmos ingredientes (Tab. I) diferindo apenas quanto às suplementações de zero, 50, 100 e $200 \mathrm{mg}$ de ácido ascórbico revestido de palmitato (Nutrimais) $/ \mathrm{kg}$ de ração. A ração foi misturada e estocada em "freezer" a $-20^{\circ} \mathrm{C}$ para peletização de acordo com a necessidade.

Tabela I. Composic̣ão da dieta experimental.

\begin{tabular}{lc}
\hline \multicolumn{1}{c}{ Ingredientes } & Porcentagem \\
\hline Farelo de milho & 18 \\
Farelo de arroz & 17 \\
Farelo de trigo & 13 \\
Farelo de soja & 26 \\
Farinha de peixe & 10 \\
Levedura & 15 \\
Premix sem vitamina C & 1 \\
\hline
\end{tabular}

Os peixes foram pesados e medidos a cada 28 dias. A alimentação foi feita diariamente (pela manhã e à tarde) à vontade, de forma controlada e observando se os animais estavam se alimentando, para que não houvesse acúmulo ou perda de ração. O consumo alimentar dos peixes dos quatro tratamentos durante o período experimental foi o seguinte: peixes sem suplementação de ácido ascórbico (5265g), peixes alimentados com $50 \mathrm{mg}$ de ácido ascórbico/kg de ração ( $7445 \mathrm{~g}$ ), peixes alimentados com $100 \mathrm{mg}$ de ácido ascórbico $/ \mathrm{kg}$ de ração $(7785 \mathrm{~g})$ e peixes alimentados com $200 \mathrm{mg}$ de ácido ascórbico/ $\mathrm{kg}$ de ração consumiram $7775 \mathrm{~g}$ de ração. $\mathrm{O}$ teor de matéria orgânica na água foi mantido em níveis baixos porque a água era escoada pelo fundo dos aquários, por meio de sifonamento, a cada dois dias. Após cada biometria, procedeu-se à lavagem dos aquários para remoção do material que não tivesse sido retirado por sifonamento.

Com as biometrias regulares dos peixes foi feita observação cuidadosa, segundo TACON (1985), de eventuais anormalidades esqueléticas, hemorragias, alterações dérmicas ou qualquer outro sinal de deficiência. Ao final do experimento, o sangue de uma amostragem de 60 animais coletados ao acaso (três de cada aquário), anestesiados previamente com 50mg de MS-222/1 de água (UNTERGASSER 1989), toi coletado por punção da veia caudal com agulha e seringa de vidro heparinizadas. Para a coleta sangüínea procurou-se não ultrapassar o tempo de três minutos, a fím de que não houvesse maiores alterações provocadas pelo estresse de manejo. As análises de variância e regressão foram procedidas 
com base nas médias dos valores de três peixes de cada aquário e processadas nas cinco repetições de cada tratamento. Foram coletadas duas amostras de sangue de cada peixe $(n=60)$ para extensão sangüínea em lâmina de microscopia, coloração por Rosenfeld (dez minutos puro, cinco minutos diluído em água) e posterior contagem diferencial de leucócitos. Somente foram contadas as células bem preservadas e de fácil identificação. Duas amostras de sangue de cada peixe $(n=60)$ foram adicionadas em capilares de vidro, centrifugados por cinco minutos em centrífuga de micro-hematócrito para posterior determinação do hematócrito através de tabela específica. Outra amostra de 1,5 a 2,0 $\mathrm{ml}$ de sangue de cada peixe $(n=60)$ foi coletada em frasco de vidro e refrigerada para determinação da taxa de hemoglobina pelo método da cianometa-hemoglobina e contagem do número de eritrócitos através da câmara de Neubauer. As fórmulas utilizadas para o cálculo de volume corpuscular médio (VCM), hemoglobina corpuscular média (HCM) e concentração de hemoglobina corpuscular média (CHCM) foram as seguintes:

$$
\begin{aligned}
& \text { VCM }=\frac{\text { hematócrito } .1000}{\text { número de hemáceas }\left(10^{12} \mathrm{n}\right)} \quad H C M=\frac{\text { hemoglobina }(g /)}{\text { número de eritrócitos }\left(10^{12} \mathrm{I}\right)} \\
& \text { CHCM }=\frac{\text { hemoglobina }(g /)}{\text { hematócrito }}
\end{aligned}
$$

Para a medida em micrômetros do diâmetro total dos eritrócitos e do diâmetro do núcleo dos eritrócitos, foi desenhada uma amostragem de 40 eritrócitos das extensões sangüíneas de cada tratamento, em câmara clara acoplada ao microscópio óptico Wild. A fórmula utilizada para obtenção destes dados foi:

$A=\frac{\pi \cdot D 1 \cdot D 2}{4} ;$ onde $\mathrm{Dl}=$ comprimento total, D2 = largura total e $\pi=3,1416$.

\section{RESULTADOS E DISCUSSÃO}

A temperatura da água dos aquários manteve-se entre $28,2^{\circ}$ e $31,0^{\circ} \mathrm{C}, \mathrm{pH}$ de 7,05 a 8,40; condutividade elétrica de 180,10 a $195,55 \mu \mathrm{S} / \mathrm{cm}$; alcalinidade de 84,70 a $94,16 \mathrm{mg} / \mathrm{l}$ e oxigênio dissolvido de 3,50 a $6,10 \mathrm{mg} / \mathrm{l}$. Ao final do experimento, os peixes suplementados com 50,100 e 200mg de ácido ascórbico/kg de ração apresentaram maior crescimento $(\mathrm{P}<0,05)(8,22,8,20$ e $8,40 \mathrm{~cm}$ respectivamente) quando comparados com os peixes não suplementados, que apresentaram $5,96 \mathrm{~cm}$. Pelos dados da tabela II, a suplementação de $50 \mathrm{mg}$ de ácido ascórbico $/ \mathrm{kg}$ de ração sugere um aumento no volume corpuscular médio, hemoglobina corpuscular média e concentração de hemoglobina corpuscular média, embora o estudo da análise de variância dos dados não tenha sido significativo $(\mathrm{P}>0,05)$. Anormalidades nos índices hematimétricos foram constatadas por alguns autores em peixes com deficiência de vitamina $C$. Com relação ao hematócrito, observouse uma tendência deste ser mais baixo (Tab. II) nos peixes alimentados com zero e 50mg de ácido ascórbico/ $\mathrm{kg}$ de ração, o que confirmou os estudos de HILTON et al. (1978), Agrawal \& Mahajan (1980) e Mustin \& Lovell (1992). Andrews \& MURAI (1975) observaram discreta diminuição do hematóc rito em I. punctatus alimentados com 30mg de ácido ascórbico/kg de ração em comparação com os peixes que receberam doses maiores da vitamina. 
Tabela II. Volume corpuscular médio (VCM), hemoglobina corpuscular média (HCM), concentração de hemoglobina corpuscular média (CHCM), hematócrito ( $\mathrm{HCT}$ ), número de eritrócitos (NE) e taxa de hemoglobina (TXH) de P. mesopotamicus.

\begin{tabular}{|c|c|c|c|c|c|c|}
\hline $\begin{array}{l}\mathrm{mg} \text { de ácido } \\
\text { ascórbico/kg de ração }\end{array}$ & $\begin{array}{l}\operatorname{VCM} \\
(\mathrm{fl})\end{array}$ & $\begin{array}{l}\mathrm{HCM} \\
(\mathrm{pg})\end{array}$ & $\begin{array}{l}\mathrm{CHCM} \\
(\mathrm{g} / \mathrm{dl})\end{array}$ & $\begin{array}{l}\mathrm{HCT} \\
(\%)\end{array}$ & $\begin{array}{c}\mathrm{NE} \\
\left(10^{6} / \mathrm{mm}^{3}\right)\end{array}$ & $\begin{array}{l}\mathrm{TXH} \\
(\mathrm{g} / \mathrm{l})\end{array}$ \\
\hline 0 & $148,20 \mathrm{a}$ & $31,30 \mathrm{a}$ & 21,40 a & $35,90 \mathrm{a}$ & 2,46 a & $7,60 \mathrm{a}$ \\
\hline 50 & $162,70 \mathrm{a}$ & 35,10 a & $26,70 \mathrm{a}$ & $34,80 \mathrm{a}$ & 2,18 a & $7,60 \mathrm{a}$ \\
\hline 100 & $149,60 \mathrm{a}$ & $33,00 \mathrm{a}$ & 22,10 a & 38,30 a & $2,59 \mathrm{a}$ & $8,45 \mathrm{a}$ \\
\hline 200 & $151,70 \mathrm{a}$ & 30,40 a & $20,10 \mathrm{a}$ & $39,00 \mathrm{a}$ & 2,58 a & $7,82 \mathrm{a}$ \\
\hline Teste F & $0,38^{\mathrm{ns}}$ & $1,23^{\mathrm{ns}}$ & $0,59^{\mathrm{ns}}$ & $1,16^{\mathrm{ns}}$ & $2,28^{\mathrm{ns}}$ & $1,47^{\mathrm{ns}}$ \\
\hline C.V. $(\%)$ & 15,66 & 12,83 & 61,45 & 11,00 & 11,44 & 9,43 \\
\hline
\end{tabular}

*. Médias seguidas de mesma letra não diferem entre si pelo teste de Tukey a 0,05 de probabilidade; (ns) valor estatisticamente não significatico.

O VCM, HCM e CHCM dos peixes suplementados com 100 e $200 \mathrm{mg}$ de ácido ascórbico/kg de ração, que mostraram diminuição em relação aos peixes suplementados com 50mg de ácido ascórbico/kg de ração, contrastam com os dados de literatura, que mostram que peixes carentes em vitamina $\mathrm{C}$ apresentam estes valores sangüíneos mais baixos do que peixes suplementados foi caracterizado como anemia (HILTON et al. 1978; ROSENLUND et al. 1990). AgRAWAL \& MAHAJAN (1980) também observaram VCM aumentado em peixes não suplementados, como relatado neste trabalho. O valores de VCM, HCM e CHCM do pacu sem suplementação de vitamina $C$ foram próximos aos dos peixes com suplementações de 100 e $200 \mathrm{mg}$ de ácido ascórbico/kg de ração (Tab. II), também relatado em $P$. platessa (ROSENLUND et al. 1990), nos quais animais sem suplementação não apresentaram diferença significativa na hemoglobina quando comparados com os peixes suplementados com 2000mg de ácido ascórbico/kg de ração. Em contrapartida observou-se que, apesar de maiores valores de VCM, HCM e CHCM os peixes com suplementação de $50 \mathrm{mg}$ de ácido ascórbico/kg de ração, apresentaram menores valores de número de eritrócitos (Tab. II), embora a diferença não tenha sido significativa entre os tratamentos. Já AGRAWAL \& MAHAJAN (1980) relataram diminuição no número de eritrócitos em alevinos de C. mrigala alimentados sem vitamina C na dieta. A comparação entre estes resultados com $P$. mesopotamicus e as outras espécies de peixe demonstraram que os valores sangüíneos podem variar de acordo com a espécie que se trabalha e as condições experimentais. Estudando o desempenho dos peixes durante o experimento, a análise de regressão permitiu estabelecer uma relação entre vitamina $C(X)$ e o crescimento $(Y)$ dos peixes $\left(Y=6,15+0,0379 X-0,000136 X^{2}\right.$, $\mathrm{R}^{2}=0,8813$ ), sugerindo que $139 \mathrm{mg}$ de vitamina $\mathrm{C} / \mathrm{kg}$ de ração foi necessário para o melhor desempenho.

Não foram observadas diferenças na morfologia geral dos eritrócitos de $P$. mesopotamicus nos diferentes tratamentos; opondo-se a dados de literatura registrados para $O$. mykiss segundo os quais a deficiência de vitamina $\mathrm{C}$ provocou formação irregular dos eritrócitos (DABRowsKi et al. 1990). Porém, a análise de variância e regressão do diâmetro dos eritrócitos mostrou células macrocíticas com 


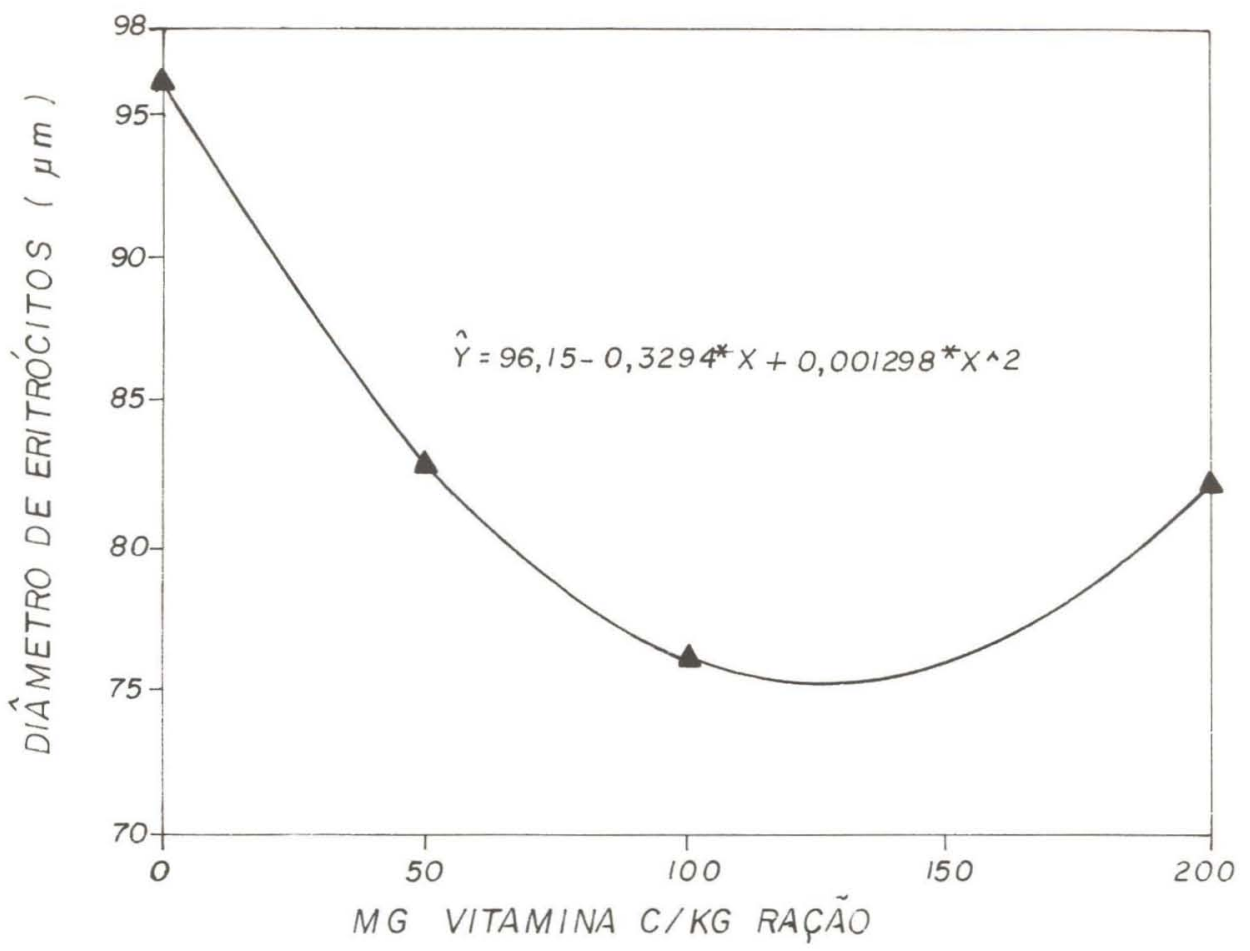

Fig. 1. Diâmetro de eritrócitos de P. mesopotamicus alimentados com diferentes níveis de vitamina $\mathrm{C}$.

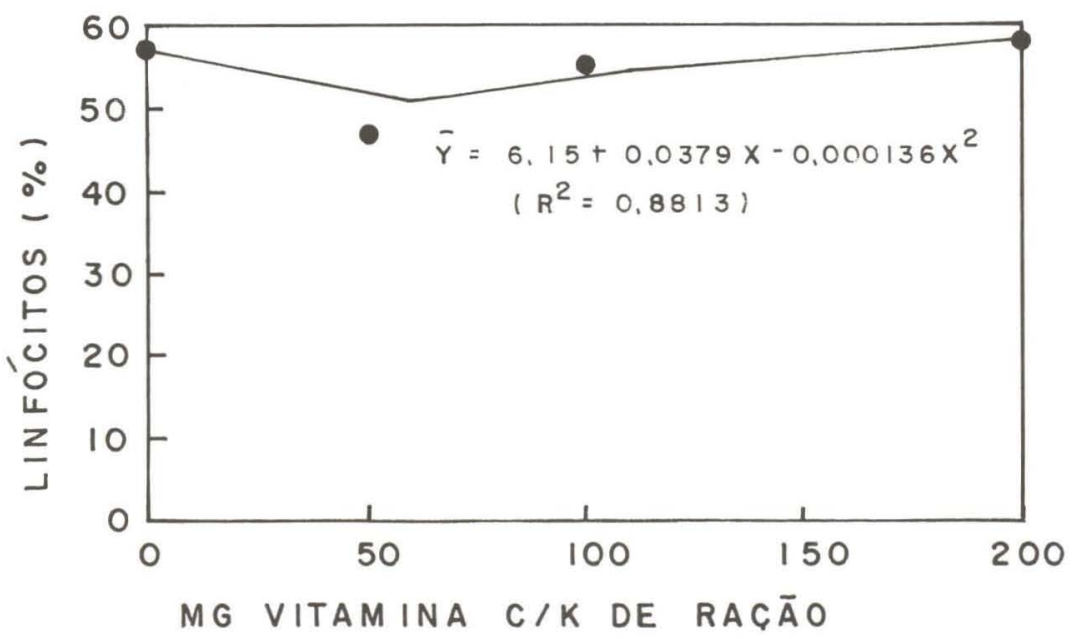

Fig. 2. Porcentagem de linfócitos sangüíneos de $P$. mesopotamicus alimentados com diferentes níveis de vitamina $C$. 
aumento significativo $(\mathrm{P}<0,05)$ (Tab. III) nos peixes sem suplementação de vitamina $\mathrm{C}$, como mostra a figura 1 , corroborando os dados registrados para $C$. mrigala (AGRAWAL \& MAHAJAN 1980). Já o diâmetro do núcleo dos eritrócitos dos peixes dos tratamentos com zero e $200 \mathrm{mg}$ de ácido ascórbico $/ \mathrm{kg}$ de ração foi significativamente maior $(\mathrm{P}<0,05)$ do que o dos peixes dos tratamentos com 50 e $100 \mathrm{mg}$ de ácido ascórbico/kg de ração (Tab. III), o que dificultou uma interpretação lógica deste parâmetro, que se interrelacionam através da equação $Y=13,59-0,1527 X+0,001934 X^{2}-0,000006 X^{3}$.

Tabela III. Diâmetro médio de eritrócitos e diâmetro médio do núcleo de eritrócitos de $P$. mesopotamicus alimentados com diferentes niveis de vitamina C.

\begin{tabular}{ccc}
$\begin{array}{c}\text { mg de ácido } \\
\text { ascórbico/kg de ração }\end{array}$ & $\begin{array}{c}\text { Diâmetro de eritrócitos } \\
(\mu \mathrm{m})\end{array}$ & $\begin{array}{c}\text { Diâmetro do núcleo } \\
\text { de eritrócitos }\end{array}$ \\
\hline 0 & $96,90 \mathrm{a}$ & $13,58 \mathrm{a}$ \\
50 & $80,94 \mathrm{~b}$ & $10,06 \mathrm{c}$ \\
100 & $77,69 \mathrm{~b}$ & $11,86 \mathrm{~b}$ \\
200 & $81,96 \mathrm{~b}$ & $14,05 \mathrm{a}$ \\
\hline Teste F & $17,53^{*}$ & $16,20^{\star}$ \\
C.V. (\%) & 15,30 & 23,04 \\
\hline
\end{tabular}

*. Médias seguidas de mesma letra não diferem entre si pelo teste de Tukey a 0,05 de probabilidade.

No que diz respeito à contagem diferencial de leucócitos sangüíneos pode-se observar que não houve diferença significativa $(P>0,05)$ na porcentagem de monócitos, linfócitos e eosinófilos (Tab. IV) entre os quatro tratamentos, ou seja, nestas condições experimentais a suplementação de vitamina $C$ na dieta não exerceu influência sobre estas células. Não foi possível uma relação consistente entre a porcentagem de linfócitos (Fig. 2) e a vitamina C, já que estas células são de importância para o sistema imunológico dos animais. Porém, a porcentagem de neutrófilos foi significativamente menor $(\mathrm{P}<0,05)$ nos peixes sem suplementação de vitamina $C$, como mostra a figura 3 .

Assim, as suplementações de 50 e $100 \mathrm{mg}$ de ácido ascórbico $/ \mathrm{kg}$ de ração resultaram em maior porcentagem destas células polimorfonucleares de importância no sistema fagocitário dos peixes (ElLIS 1977). NUNGESTER \& AMES (1948), GANGULy et al. (1976) e SHILOTRI (1977) já haviam verificado, em cobaias da Índia, a importância da suplementação de vitamina $\mathrm{C}$ na resposta inflamatória de migração e na fragilidade dos leucócitos, que dependeram diretamente do teor de vitamina C oferecido aos animais. AGRAWAL \& MAHAJAN (1980) relataram que peixes, como $C$. mrigala carentes em vitamina $C$ apresentaram leucopenia acompanhada de redução de linfócitos e trombócitos mas ao contrário do pacu, observaram aumento na porcentagem de neutrófilos nos peixes que não receberam suplementação. Estes autores comentaram ainda que leucopenia, leucocitose, trombopenia e trombocitose têm ambas sido observadas em pacientes escorbúticos (Chatterjee 1967; Cox 1968, citados por Agrawal \& Mahajan 1980), 


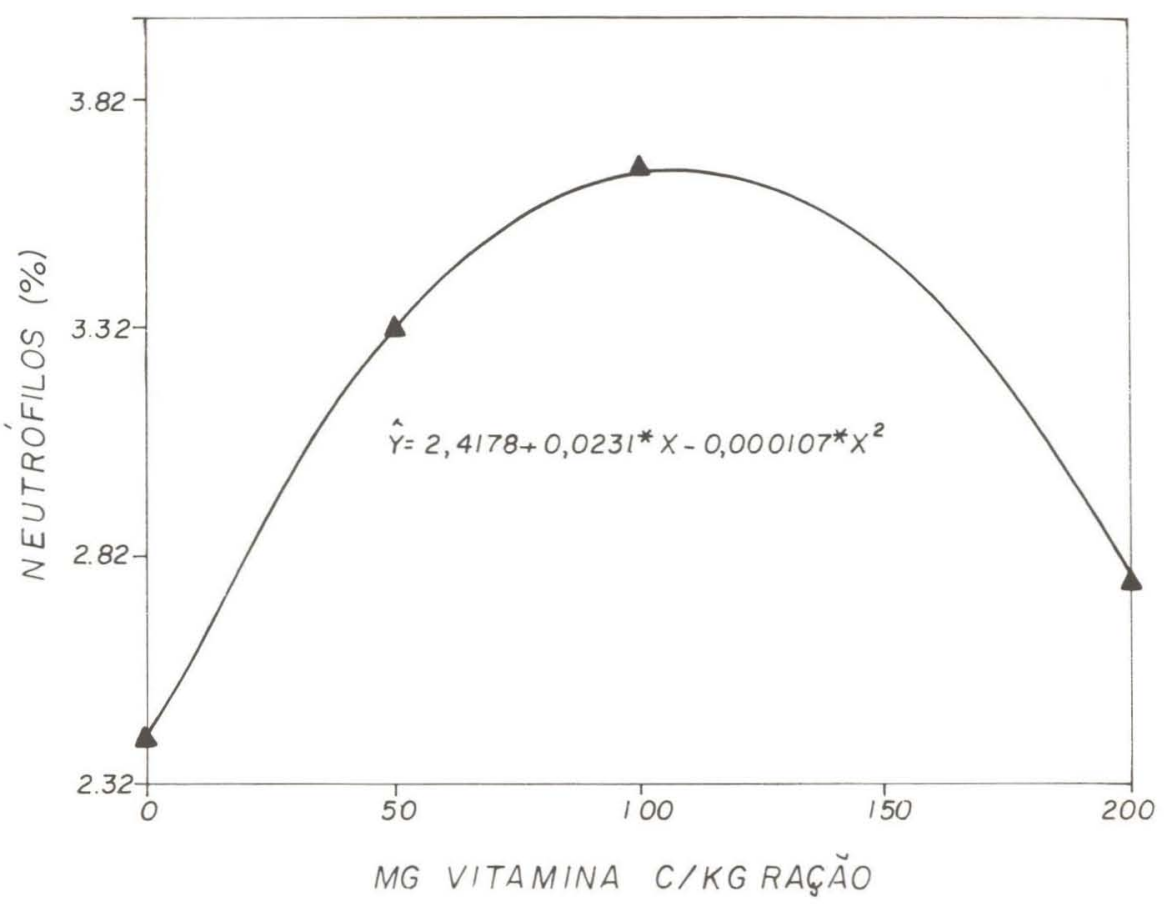

Fig. 3. Porcentagem de neutrófilos sangüineos de $P$. mesopotamicus alimentádos com diferentes niveis de vitamina $\mathrm{C}$.

Tabela IV. Contagem diferencial de leucócitos de $P$. mesopotamicus submetidos a diferentes níveis de vitamina $C$ na ração.

\begin{tabular}{|c|c|c|c|c|}
\hline $\begin{array}{c}\mathrm{mg} \text { de ácido } \\
\text { ascórbico/kg de ração }\end{array}$ & $\begin{array}{c}\text { Monócitos } \\
(\%)\end{array}$ & $\begin{array}{l}\text { Linfócitos } \\
(\%)\end{array}$ & $\begin{array}{c}\text { Eosinófilos } \\
(\%)\end{array}$ & $\begin{array}{c}\text { Neutrófilos } \\
(\%)\end{array}$ \\
\hline 0 & 27,25 a & 57,00 a & $7,91 \mathrm{a}$ & $2,32 \mathrm{~b}$ \\
\hline 50 & 28,41 a & 46,92 a & 5,35 a & $3,60 \mathrm{a}$ \\
\hline 100 & $22,85 \mathrm{a}$ & 54,91 a & 8,56 a & 3,47 a \\
\hline 200 & $24,20 \mathrm{a}$ & $58,06 \mathrm{a}$ & 9,11 a & $2,82 a b$ \\
\hline Teste F & $0,83^{\mathrm{ns}}$ & $1,09^{\mathrm{ns}}$ & $0,90^{\mathrm{ns}}$ & $7,52^{*}$ \\
\hline C.V. $(\%)$ & 19,33 & 15,19 & 37,12 & 24,88 \\
\hline
\end{tabular}

${ }^{*}$. Médias seguidas de mesma letra não diferem entre si pelo teste de Tukey a 0,05 de probabilidade; (ns) valor estatisticamente não significativo.

interpretações também sugestivas para os resultados do pacu. Não obstante, o aumento na porcentagem de neutrófilos em $P$. mesopotamicus sugere uma provável melhora no sistema de defesa (HAM 1972; ROBERTS 1981) dos peixes dos tratamentos com suplementações de 50 e $100 \mathrm{mg}$ de ácido ascórbico $/ \mathrm{kg}$ de ração. Portanto, os resultados sugerem que $50 \mathrm{mg}$ de ácido ascórbico/ $\mathrm{kg}$ de ração para o pacu é o nível recomendado para o bom desenvolvimento e manutenção das 
respostas hematológicas. Maiores estudos deverão ser feitos com as espécies brasileiras, particularmente as cultivadas a fim de comprovar a importância da vitamina $\mathrm{C}$ na dieta e indicar para cada uma a quantidade necessária e viável a ser incluída na dieta.

AGRADECIMENTO. Os autores agradecem ao Prof. Dr. Sérgio do Nascimento Kronka do Departamento de Ciêneias Exatas da Unesp, Campus de Jaboticabal (São Paulo). pelo auxílio nas análises estatísticas. Financiado pela FAPESP processo 1601-0/92.

\section{REFERÊNCIAS BIBLIOGRÁFICAS}

Agrawal, N.K. \& C.L. Mahajan. 1980. Nutritional deficiency disease in an indian major carp, Cirrhina mrigala Hamilton, due to avitaminosis $\mathrm{C}$ during early growth. J. Fish Dis. 3: 231-248.

ANDREWS, J.W. \& T. MuraI. 1975. Studies on the vitamin C requirements of channel catfish (Ictalurus punctatus). J. Nutr. 105: 557-561.

ChATTERJEe, G.C. 1967. Effects of ascorbic acid deficiency in animals, p.407456. In: W.H. Sebrell JR. \& R.S. Harris (ed.). The Vitamins. New York, Academic Press, vol. I.

COX, E.V. 1968. The anemia of scurvy, p. 635-651. In: R.S. HARRIS; I.G. WOOL \& J.A. Loraine (ed.). Vitamins and Hormones. New York, Academic press, vol. 26.

Dabrowski, K.; N. El-Fiky; G. Kock; M. Frigg \& W. Wieser. 1990. Requirement and utilization of ascorbic acid and ascorbic sulfate in juvenile rainbow trout. Aquaculture 91: 317-337.

Durve, V.S. \& R.T. LOVELL. 1982. Vitamin C and disease resistance in channel catfish (Ictalurus punctatus). Can. J. Fish. Aquat. Sci. 39 (7): 948-951.

Ellis, A.E. 1977. The leucocytes of fish: a review. J. Fish Biol. 11: 453-491.

EL NagGaR, G.O. \& R.T. LovELL. 1991. L-ascorbyl-2-monophosphate has equal antiscorbutic activity as L-ascorbic acid but L-ascorbyl-2-sulfate is inferior to L-ascorbic acid for channel catfish. J. Nutr. 121: 1622-1626.

Ganguly, R.; M.F. DurieuX \& R.H. Waldman. 1976. Macrophage function in vitamin $C$ deficient guinea pigs. Am. J. Clin. Nutr. 29: 762-765.

Golterman, H.L.; R.S. Clymo \& M.A. Ohnstad. 1978. Methods for physical and chemical analysis of freshwater. Oxford, Blackwell Scientific Publications, 2nd. ed., 213p.

Ham, A.W. 1972. Histologia. Rio de Janeiro, Guanabara Koogan, $6^{\text {a }}$ ed., 990p. Hilton, J.W.; C.Y. ChO \& S.J. Slinger. 1978. Effect of graded levels of supplemental ascorbic acid in practical diets fed to rainbow trout (Salmo gairdneri). J. Fish. Res. Board Can. 35 (4): 431-436.

LI, Y. \& R.T. LovelL. 1985. Elevated levels of dietary ascorbic acid increase immune responses in channel catfish. J. Nutr. 115: 123-131.

Lovell, R.T. 1982. Elevated levels of vitamin C increase disease resistance in channel catfish. Highlights of Agricultural Research 29 (1). 
LovelL, R.T. \& C. LIM. 1978. Vitamin C in pond diets for channel catfish. Trans. Am. Fish. Soc. 107 (2): 321-325.

MARTINS, M.L. (in press). Effects of ascorbic acid defeciency on the growth, gill filament lesions and behaviour of pacus fry (Piaractus mesopotamicus Holmberg, 1887). Braz. J. Med. Biol. Res..

MILLIKIN, M.R. 1982. Qualitative and quantitative nutrient requirements of fishes: a review. Fish. Bull. 80 (4): 655-686.

Mustin, W.G. \& R.T. Lovell. 1992. Na-L-ascorbyl-2-monophosphate as a source of vitamin $C$ for channel catfish. Aquaculture 105: 95-100.

Navarre, O. \& J.E. Halver. 19889. Disease resistance and humoral antibody production in rainhow trout fed high levels of vitamin C. Aquaculture 79: 207-221.

Nungester, W.J. \& A.M. AmEs. 1948. The relationship between ascorbic acid and phagocytic activity. J. Infect. Dis. 83: 50-59.

Roberts, R.J. 1981. Patologia de los peces. Madrid, Ediciones Mundi-Prensa, $366 \mathrm{p}$.

Rosenlund, G.; L. Jorgensen; R. WaAgBo \& K. Sandnes. 1990. Effects of different dietary levels of ascorbic acid in place (Pleuronectes platessa L.). Comp. Biochem. Physiol. 96A (3): 395-398.

ShILOTRI, P.G. 1977. Phagocytosis and leukocyte enzimes in ascorbic acid deficient guinea pigs. J. Nutr. 107: 1513-1516.

TACON, A.G.J. 1985. Nutritional fish pathology. Morphological signs of nutrient deficiency and toxicity in farmed fish. Rome, FAO, ADCP, REP/85/22, 33p.

Untergasser, D. 1989. Handhook of Fish Diseases. U.S.A., TFH Publications, 160 p.

Recebido em 30.XI.1994; aceito em 01.X.1995. 